\title{
Comparison of Exergy and Advanced Exergy Analysis in Three Different Organic Rankine Cycles
}

\author{
Shahab Yousefizadeh Dibazar ${ }^{1}$, Gholamreza Salehi ${ }^{2}$ and Afshin Davarpanah ${ }^{3, *(1)}$ \\ 1 Energy System Engineering Department, Petroleum University of Technology, Abadan, Iran; \\ shahab.yousefizadeh@gmail.com \\ 2 Department of Mechanical Engineering, Central Tehran Branch, Islamic Azad University, Tehran, Iran; \\ gh.salehi@iauctb.ac.ir \\ 3 Department of Mathematics, Aberystwyth University, Aberystwyth SY23 3BZ, UK \\ * Correspondence: afd6@aber.ac.uk
}

Received: 17 April 2020; Accepted: 9 May 2020; Published: 14 May 2020

\begin{abstract}
Three types of organic Rankine cycles (ORCs): basic ORC (BORC), ORC with single regeneration (SRORC) and ORC with double regeneration (DRORC) under the same heat source have been simulated in this study. In the following, the energy and exergy analysis and the advanced exergy analysis of these three cycles have been performed and compared. With a conventional exergy analysis, researchers can just evaluate the performance of components separately to find the one with the highest amount of exergy destruction. Advanced analysis divides the exergy destruction rate into unavoidable and avoidable, as well as endogenous and exogenous, parts. This helps designers find more data about the effect of each component on other components and the real potential of each component to improve its efficiency. The results of the advanced exergy analysis illustrate that regenerative ORCs have high potential for reducing irreversibilities compared with BORC. Total exergy destruction rates of $4.13 \mathrm{~kW}(47 \%)$ and $5.25 \mathrm{~kW}(45 \%)$ happen in avoidable/endogenous parts for SRORC and DRORC, respectively. Additionally, from an advanced exergy analysis viewpoint, the priority of improvement for system components is given to turbines, evaporators, condensers and feed-water heaters, respectively.
\end{abstract}

Keywords: exergy; advanced exergy analysis; organic Rankine cycle; regenerative cycle

\section{Introduction}

Energy is known to be one of the most important elements in the development of any society. In recent years, many researchers have conducted many studies to discover ways to reduce energy consumption in different sections. Studies on industries have shown that a great amount of waste heat is generated during various processes that are placed in low-temperature ranges. This waste heat, which is released to the ambience directly, in many cases, causes a lot of problems for the environment, such as thermal pollution, ozone depletion, air pollution and so on [1]. There are some suggestions to use low-temperature waste heats, but recovering by organic Rankine cycles (ORCs) to produce power is offered as one of the best ways to increase process efficiency [2-4]. In the last two decades, different systems of ORCs have been studied widely by researchers, and their focus are more on working fluids of cycles and optimizing performance conditions [5-9]. Biomass, solar thermal energy and geothermal are some other heat sources for ORC applications to produce electricity [10]. The energy conservation law is not sufficient by itself, so the second low should be considered to have a wide view to design systems [11]. Huan et al. [12] selected a regenerative organic Rankine cycle (RORC) to analyze energy and exergy aspects of cycles with six different working fluids. In their study, they optimized the exergy efficiency of the cycles to find the best condition ranges for the inlet pressure and temperature of the 
turbines. R141b and R11 are suggested as better working fluids for systems, and the maximum exergy of $56.87 \%$ was obtained for ORC with double regeneration (DRORC). In another study by Roy et al. [13], inlet temperature in turbines and superheat in RORC were optimized. It was observed that R123, as working fluid of the system, showed its best performance at 2.5 MPa pressure at the evaporator compared with R123a. In 2011, Rashidi et al. [14] have investigated optimizing RORC using artificial bee colony-based neural network method. Results indicated that, for RORC, there is an optimum range for bleed pressure to reach the maximum thermal and exergy efficiency with the highest power output. If the pressure goes above or below this range, the thermal performance of the system will get worse.

As it is seen, most studies consider a conventional exergy analysis for ORCs. A conventional exergy analysis can just evaluate the performance of system components separately to find the component with the highest exergy destruction. This method does not show the share of each component of a system on other components' exergy loss. An advanced analysis divides exergy loss into unavoidable and avoidable and exogenous and endogenous for each component. By this analysis, the potential of each component is observed and discussed to improve its efficiency [15]. Conventional and advanced exergy analysis for gas turbines in different systems has been applied by Fallah et al. [16]. Among those systems, gas turbines with evaporative inlet air cooling have the best potential to reduce their destruction. It was also concluded that, when using an advanced exergy analysis, working conditions obtained by optimization for inlet cooling components were different from those obtained by a conventional exergy analysis. Galindo et al. [17] had discussed conventional and advanced exergy analysis in ORC as a bottoming cycle in an internal combustion (IC) engine in 2016. They indicated that boilers have the highest exergy destruction, but turbines have great potentials to improve their efficiency. Additionally, they suggested that about $36.5 \%$ of exergy loss in a system can be reduced by only the avoidable part of exergy loss in each component. Nami et al. [18], in 2017, worked on a binary fluid organic Rankine cycle with conventional and advanced exergy analysis. In this system, the low-pressure vapor generator (LPVG) has the highest exergy destruction among the components. Additionally, the advanced exergy analysis results showed that $15 \%$ of the condenser exergy destruction is placed in avoidable parts, which consists of $7 \%$ of the whole avoidable exergy destruction rate of the system. In addition, their study shows that, from an advanced exergy analysis view, more than $70 \%$ of total exergy destruction of the system is placed in endogenous exergy destruction parts, and among all the parts of the system, the endogenous exergy destruction is higher than the exogenous exergy destruction.

By studying many papers, it was observed that RORC has a really great efficiency and a potential to recover heat from low-temperature heat sources. RORC has been investigated by energy and exergy analysis, and the system was also studied from economics aspects [19-22]. To the best of the authors' knowledge, and by reviewing many papers, there is no study which has applied advanced exergy analysis to RORC for recovering low-temperature waste heat.

Therefore, the present study attempts to explain the system conditions, the first and the second law of thermodynamics and then to model our systems. Three cycles (BORC, single-regeneration ORC (SRORC) and DRORC) are selected to do the analysis. Then, the advanced exergy analysis aspects and their applications in the cycles are discussed. It is then followed by analyzing and discussing the results about the potential of each component to find and suggest some ways of decreasing the total exergy destruction rate in order to have the best design.

\section{Description of Systems}

For recovering heat with low-temperature sources, water is not a good option as a working fluid in cycles. ORCs are suitable cycles for the conversion of low-quality heat to electricity. ORCs are similar to the conventional steam Rankine cycles, but the working fluids in these cycles are organic fluids with low boiling points. Using this kind of fluid, it is possible to use heat from lower temperature heat sources. In ORC applications, organic fluids such as alkanes, aromates and siloxanes are used as working fluids instead of water. The reason to use these fluids is that they have lower boiling temperatures and higher molecular weights compared to water, which causes higher thermodynamic 
performances in lower temperatures. Since most of the organic fluids do not go to wet regions when they are expanded in turbines, they prevent erosion in turbine blades. Additionally, compared with the steam Rankine cycles, ORC applications work under lower working fluid pressures, which leads to lower turbine costs [23].

In ORC system designing, at least five components are needed for basic types: turbines, evaporators, condensers, pumps and working fluids. In the present study, R11 is selected as the working fluid for the analysis because of its high exergy efficiency [12]. Three different ORC systems (BORC, SRORC and DRORC) are chosen in this research. The schematic of these cycles with T-S (temperature-entropy) diagrams are shown respectively in Figures 1-3. In the basic ORC, first, the fluid is heated by the evaporator, and its temperature is increased. Then, the working fluid (R11) expands in the turbine from high pressure to low pressure to produce power. The outlet flow of the turbine goes to the condenser for cooling, and the saturated liquid enters the pump. The pump increases the flow pressure to reach the evaporator pressure.
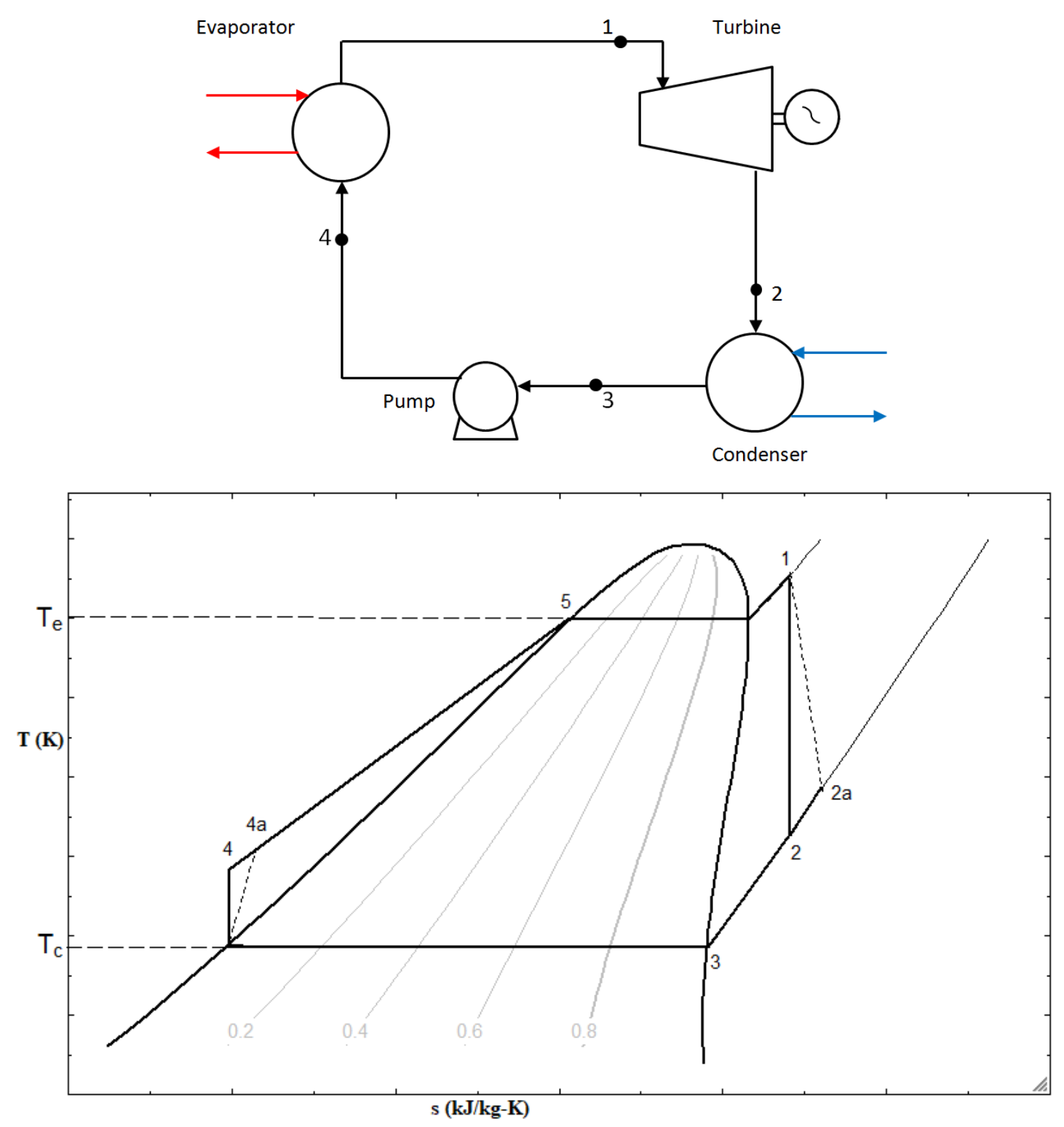

Figure 1. Schematic diagram of the cycle and T-S thermodynamic diagram of the basic organic Rankine cycle (BORC) system. 

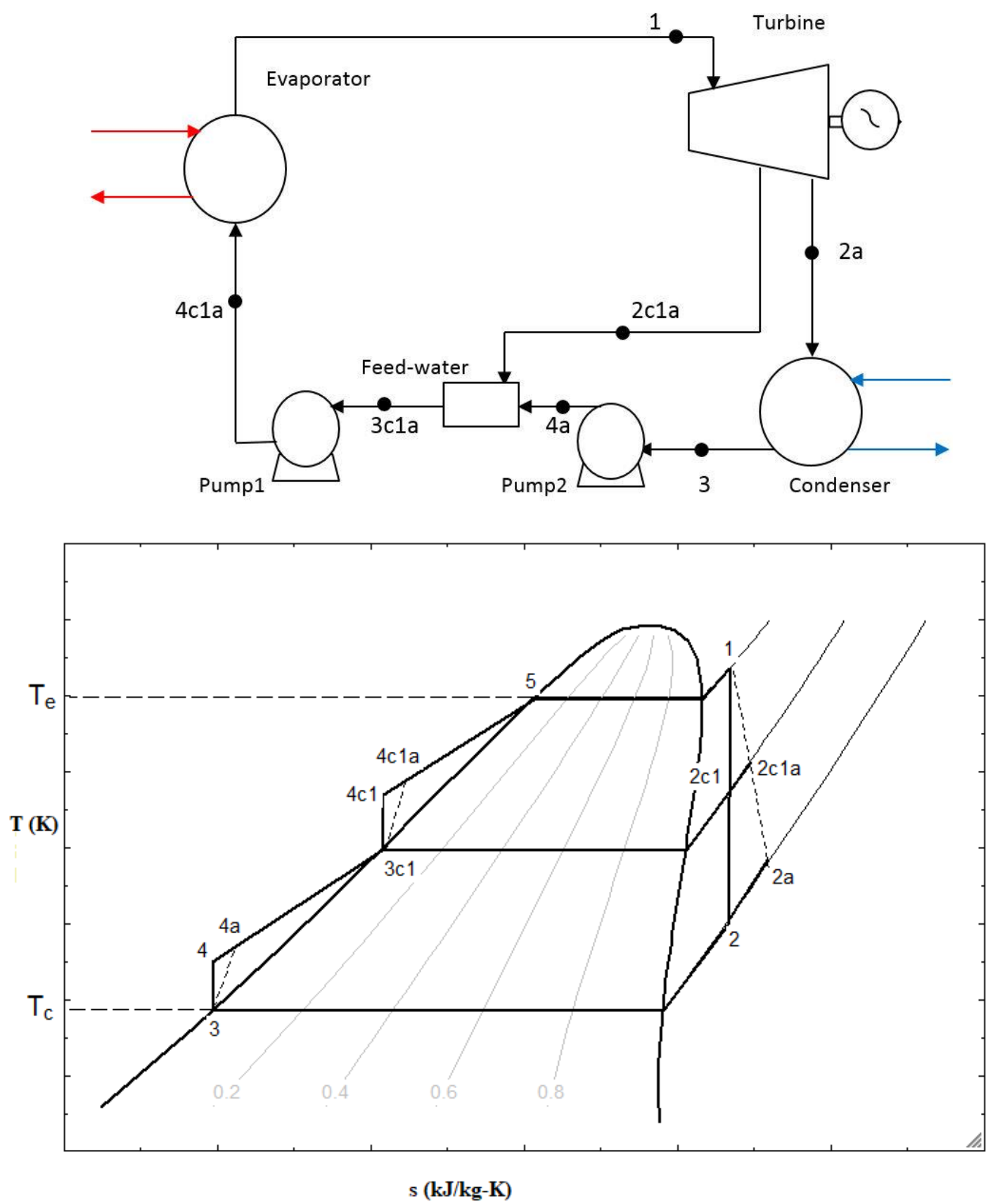

Figure 2. Schematic diagram of the cycle and T-S thermodynamic diagram of the regeneration ORC (RORC) system.

As it is seen in Figures 2 and 3, in regenerative cycles, the turbine outlet flow is split into two parts in single, and three parts in double, systems. These parts are in the vapor phase, which enters feed-water heaters to preheat the working fluid before going to the evaporator. By this method, more potential of the cycle energy is used, so a higher efficiency, compared with the basic type, is gained. In order to simulate the cycle performance in this study, the following assumptions are employed:

- All processes in cycles are assumed to be at a steady state and steady flow.

- There are no pressure drops in the pipes [24].

- Heat and friction losses, as well as the variation of potential and kinetic energies, are neglected [25].

Exiting fluid from the condenser is a saturated liquid. 

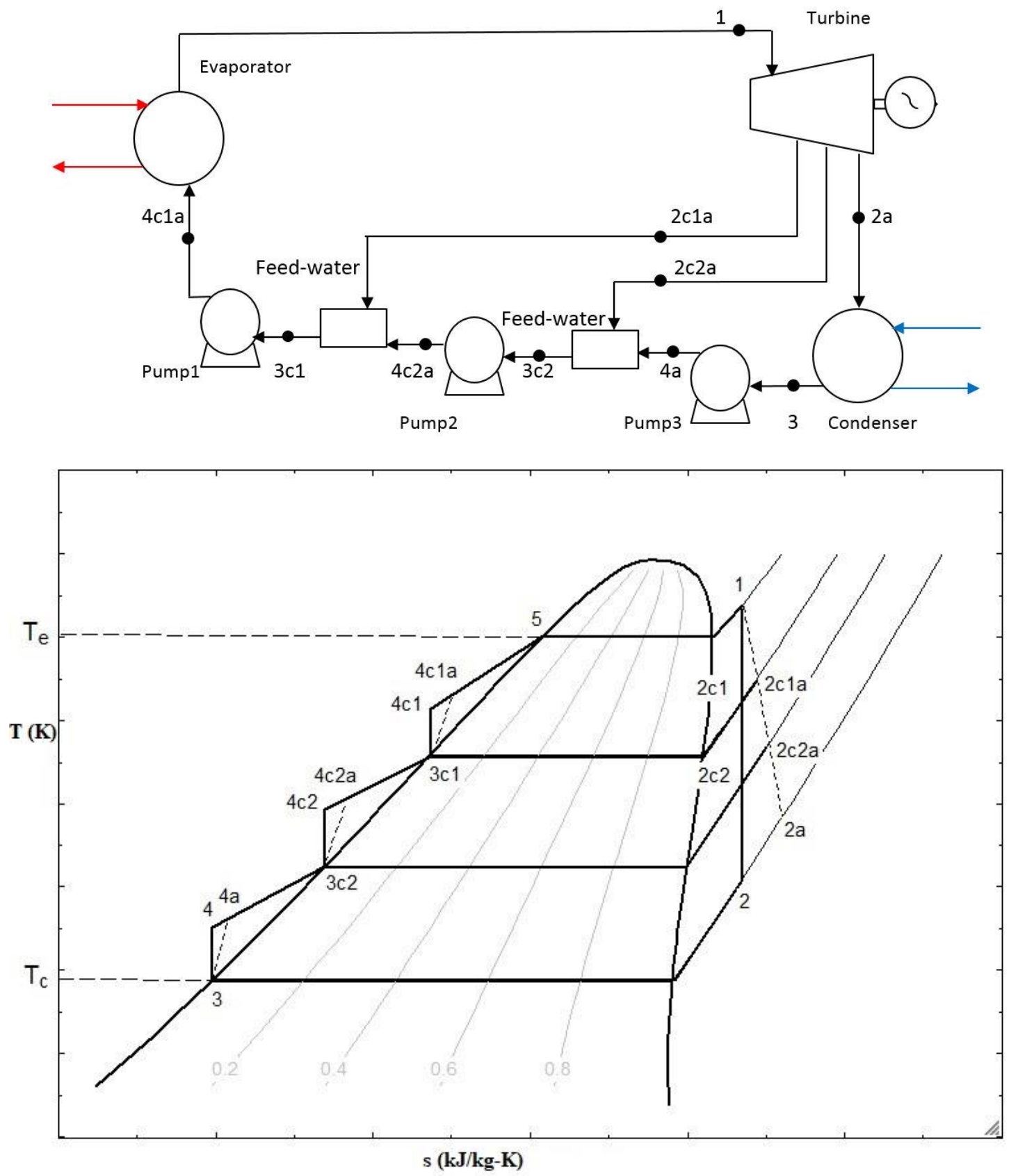

Figure 3. Schematic diagram of the cycle and T-S thermodynamic diagram of the double-regeneration ORC (DRORC) system.

\section{Energy and Exergy Analysis}

\subsection{Energy and Conventional Exergy Analysis}

The purpose of the energy analysis is to design thermal systems. However, the aim of the exergy analysis is to determine the thermodynamic efficiency of the cycles and compare them to find out the best system performance. There are two important basic laws in thermodynamics: the first and the second law. The first law analyzes the conservation of energy in processes, while the second law is used to discuss the quality of energy and materials. The main equations for energy and mass balance used in the first law analysis for a controlled volume of each component are written below:

Mass balance:

$$
\sum \dot{m}_{i}=\sum \dot{m}_{e}
$$


Energy balance:

$$
\sum \dot{Q}-\sum \dot{W}+\sum \dot{m}_{i} h_{i}-\sum \dot{m}_{e} h_{e}=0
$$

Exergy analysis has two advantages compared with the conventional energy analysis method. It provides a more precise measurement of the real inefficiencies in a system, as well as their exact places. The main goal of the second law is to recognize the place, type and quantity of energy loss resources in system processes and the factors affecting them. The exergy balance equation for a control volume of each component can be written as [24]:

$$
\dot{I}=\dot{E}_{\text {in }}-\dot{E}_{\text {out }}+\dot{E}_{Q}-\dot{E}_{W}
$$

where $\dot{I}$ is the total exergy rate of a destroyed system, and $\dot{E}_{Q}$ and $\dot{E}_{w}$ are the exergy transfer rates for heat and work, respectively. The equivalent work of any form of energy is defined as its exergy, so work is equivalent to exergy in every respect.

For a heat transfer rate $\left(\dot{Q}_{\mathrm{r}}\right)$ and system temperature where heat transfer happens $\left(\mathrm{T}_{\mathrm{r}}\right)$, the maximum rate of conversion from thermal energy to work is:

$$
\begin{gathered}
\dot{w}_{\max }=\dot{E}^{\mathrm{Q}}=Q^{\mathrm{r}} \tau \\
\tau=1-\mathrm{T}_{0} / \mathrm{T}_{\mathrm{r}}
\end{gathered}
$$

$\tau$ is called the dimensionless exergetic temperature and is equal to the Carnot efficiency for special cases when the environment is at temperature $\mathrm{T}_{0}$.

Exergy of each stream in a system, $\dot{E}$, is divided into four different parts:

$$
\dot{E}=\dot{E}_{\mathrm{k}}+\dot{E}_{\mathrm{p}}+\dot{E}_{\mathrm{ph}}+\dot{E} \mathrm{ch}
$$

where $\dot{E}_{\mathrm{k}}$ is kinetic exergy, $\dot{E}_{\mathrm{p}}$ is potential exergy, $\dot{E}_{\mathrm{ph}}$ is physical exergy and $\dot{E}_{\mathrm{ch}}$ is chemical exergy. $\dot{E}_{\mathrm{k}}$ and $\dot{E}_{\mathrm{p}}$ are associated with high-grade energies and $\dot{E}_{\mathrm{ph}}$ and $\dot{E}_{0}$ with low-grade energies. In this research, kinetic and potential exergy is neglected.

Physical exergy of each stream can be calculated from the following Equation ( 0 refers to environmental state):

$$
e_{p h}=\left(h-h_{0}\right)-T_{0}\left(S-S_{0}\right)
$$

and the chemical exergy of the mixture for ideal gas can be expressed as below:

$$
e_{c h}=\sum_{i=0}^{n} x_{i} e x_{c h i}+\mathrm{RT}_{0} \sum_{i=0}^{n} x_{i} \ln \left(x_{i}\right)
$$

Here, $x_{i}$ is the mole fraction of the ith component in the mixture, and $e x_{c h i}$ in this relation is the chemical exergy of each component. As it is seen, exergy loss depends on the amount of heat that is transferred to ambient. So, convectional exergy analysis is only influenced by the entire condition of a system and does not deal with the effect of system components on other components' exergy destructions.

The basic equations used for the kth component in the conventional exergy analysis are shown in Equations (9)-(12).

$$
\begin{gathered}
\dot{E}_{D . k}=\dot{E}_{F . k}-\dot{E}_{P . k} \\
\varepsilon_{k}=\frac{\dot{E}_{P . k}}{\dot{E}_{D . k}}=1-\frac{\dot{E}_{D . k}}{\dot{E}_{F . k}} \\
y_{k}=\frac{\dot{E}_{D . k}}{\dot{E}_{F . k}}
\end{gathered}
$$




$$
y_{k}^{*}=\frac{\dot{E}_{D . k}}{\dot{E}_{D . t o t}}
$$

In these equations, $\dot{E}_{D . k}, \dot{E}_{F . k}$ and $\dot{E}_{P . k}$ represent the exergy destruction rate, exergy of fuel and exergy of product, respectively. Additionally, $\varepsilon_{k}, y_{k}$ and $y_{k}^{*}$ are the exergy efficiency, the exergy loss ratio and the exergy of fuel with the total exergy destruction in the kth component, respectively. The exergy equations for components of the three cycles are expressed in Table 1.

Table 1. Balance of exergy for any components of the systems. BORC: basic organic Rankine cycle, SRORC: single-regeneration ORC and DRORC: double-regeneration ORC.

\begin{tabular}{|c|c|c|c|}
\hline \multirow{2}{*}{ Cycle Components } & \multicolumn{3}{|c|}{ Exergy Balance Equations } \\
\hline & BORC & SRORC & DRORC \\
\hline Evaporator & $\dot{E}_{4}+\dot{E}_{\mathrm{q}, \mathrm{Eva}}=\dot{E}_{1}+\dot{E}_{\mathrm{D}, \text { Eva }}$ & $\dot{E}_{4 \mathrm{cla}}+\dot{E}_{\mathrm{q}, \mathrm{Eva}}=\dot{E}_{1}+\dot{E}_{\mathrm{D}, \mathrm{Eva}}$ & $\dot{E}_{4 \mathrm{cla}}+\dot{E}_{\mathrm{q}, \mathrm{Eva}}=\dot{E}_{1}+\dot{E}_{\mathrm{D}, \mathrm{Eva}}$ \\
\hline Turbine & $\dot{E}_{1}=\dot{E}_{\mathrm{W}, \text { tur }}+\dot{E}_{2}+\dot{E}_{\mathrm{D}, \mathrm{Tur}}$ & $\dot{E}_{1}=\dot{E}_{\mathrm{w}, \mathrm{tur}}+\dot{E}_{2 \mathrm{a}}+\dot{E}_{2 \mathrm{cla}}+\dot{E}_{\mathrm{D}, \mathrm{Tur}}$ & $\dot{E}_{1}=\dot{E}_{\mathrm{W}, \mathrm{tur}}+\dot{E}_{2 \mathrm{a}}+\dot{E}_{2 \mathrm{cla}}+\dot{E}_{2 \mathrm{c} 2 \mathrm{a}}+\dot{E}_{\mathrm{D}, \mathrm{Tur}}$ \\
\hline Condenser & $\dot{E}_{2}=\dot{E}_{\mathrm{q}, \text { con }}+\dot{E}_{3}+\dot{E}_{\mathrm{D}, \text { cond }}$ & $\dot{E}_{2 \mathrm{a}}=\dot{E}_{\mathrm{q}, \text { con }}+\dot{E}_{3}+\dot{E}_{\mathrm{D}, \text { cond }}$ & $\dot{E}_{2 \mathrm{a}}=\dot{E}_{\mathrm{q}, \text { con }}+\dot{E}_{3}+\dot{E}_{\mathrm{D}, \text { cond }}$ \\
\hline Pump & $\dot{E}_{3}+\dot{E}_{\mathrm{W}, \text { pump }}=\dot{E}_{4}+\dot{E}_{\mathrm{D}, \text { pump }}$ & $\begin{aligned} \dot{E}_{3 \mathrm{c} 1}+\dot{E}_{\mathrm{w}, \text { pump } 1} & =\dot{E}_{4 \mathrm{cla}}+\dot{E}_{\mathrm{D}, \text { pump1 }} \\
\dot{E}_{3}+\dot{E}_{\mathrm{w}, \mathrm{pump} 2} & =\dot{E}_{4 \mathrm{a}}+\dot{E}_{\mathrm{D}, \text { pump2 }}\end{aligned}$ & $\begin{aligned} \dot{E}_{3 \mathrm{c} 1}+\dot{E}_{\mathrm{w}, \text { pump } 1} & =\dot{E}_{4 \mathrm{cla}}+\dot{E}_{\mathrm{D}, \text { pump } 1} \\
\dot{E}_{3 \mathrm{c} 2}+\dot{E}_{\mathrm{w}, \text { pump2 } 2} & =\dot{E}_{4 \mathrm{c} 2 \mathrm{a}}+\dot{E}_{\mathrm{D}, \text { pump2 }} \\
\dot{E}_{3}+\dot{E}_{\mathrm{w}, \text { pump3 } 3} & =\dot{E}_{4 \mathrm{a}}+\dot{E}_{\mathrm{D}, \text { pump3 }}\end{aligned}$ \\
\hline Feed-water heater & - & $\dot{E}_{4}+\dot{E}_{2 c 1 a}=\dot{E}_{3 c 1}+\dot{E}_{\mathrm{D}, \text { feed-water }}$ & $\begin{array}{c}\dot{E}_{4 \mathrm{c} 2 \mathrm{a}}+\dot{E}_{2 \mathrm{c} 1 \mathrm{a}}=\dot{E}_{3 \mathrm{c} 1}+\dot{E}_{\mathrm{D}, \text { feed-water1 }} \\
\dot{E}_{4 \mathrm{a}}+\dot{E}_{2 \mathrm{c} 2 \mathrm{a}}=\dot{E}_{3 \mathrm{c} 2}+\dot{E}_{\mathrm{D}, \text { feed-water2 }}\end{array}$ \\
\hline
\end{tabular}

In order to observe the system performance for the research, the first and the second law efficiencies are calculated from the equations below [12]:

$$
\begin{gathered}
\eta_{t}=\frac{W_{\text {net }}}{Q} \\
\eta_{e}=W_{\text {net }} /\left[Q\left(1-\frac{T_{0}}{T_{m}}\right)\right]
\end{gathered}
$$

where $T_{0}$ is environmental temperature, and $T_{m}$ is source of heat; mean temperature can be calculated by the following equation:

$$
T_{m}=\left(T_{\text {in }}-T_{\text {out }}\right) / \ln \left(T_{\text {in }} / T_{\text {out }}\right)
$$

By the uses of Equations (13) and (14), the energy efficiency and exergy efficiency for the basic cycle can be obtained:

$$
\begin{gathered}
\eta_{t}=W_{\text {net }} / Q \\
\eta_{e}=\frac{W_{\text {net }}}{Q}\left(1-\frac{T_{0}}{T_{m}}\right)
\end{gathered}
$$

For SRORC, the first and the second law efficiencies are presented as:

$$
\begin{gathered}
\eta_{t}=\frac{W_{\text {net }}}{Q}=\frac{W_{t}-W_{p 1}-W_{p 2}}{Q} \\
\eta_{e}=\frac{W_{\text {net }}}{Q\left(1-\frac{T_{0}}{T_{m}}\right)}=\frac{W_{t}-W_{p 1}-W_{p 2}}{\left[Q\left(1-\frac{T_{0}}{T_{m}}\right)\right]}
\end{gathered}
$$

For DRORC, efficiencies are calculated from the equations below:

$$
\eta_{t}=\frac{W_{n e t}}{Q}=\frac{W_{t}-W_{p 1}-W_{p 2}-W_{p 3}}{Q}
$$




$$
\eta_{t}=\frac{W_{n e t}}{Q\left(1-\frac{T_{0}}{T_{m}}\right)}=\frac{W_{t}-W_{p 1}-W_{p 2}-W_{p 3}}{Q\left(1-T_{0} / T_{m}\right)}
$$

\subsection{Advanced Exergy Analysis}

By a conventional exergy analysis, the only thing the researchers can discuss is the quantity of destruction rates in systems, and this method does not give any information about the type of these losses. Advanced exergy analysis is a new method that speaks about the details of the destructions to help researchers recognize different factors that affect component losses. Generally, advanced exergy analysis divides the loss rate of each component into two parts: endogenous/exogenous and avoidable/unavoidable.

\subsubsection{Exogenous/Endogenous Exergy Destruction}

To observe the effect of the parts on each other in a system, the kth component destruction rate is split into exogenous and endogenous parts:

$$
\dot{E}_{D . k}=\dot{E}_{D . k}^{E N}+\dot{E}_{D . k}^{E X}
$$

The endogenous exergy destruction $\left(\dot{E}_{D . k}^{E N}\right)$ is the destruction rate associated with irreversibility due to inefficiency in the kth component, while all the residual components work preferably. The exogenous exergy destruction $\left(\dot{E}_{D . k}^{E X}\right)$ is related to the destruction rate that happens in the remaining components. This dividing shows the real location of destructions in the systems, so that researchers can focus on the exact parts to improve system performance. There are two ways to compute the endogenous exergy destruction rate: engineering method and thermodynamic or hybrid cycle [26]. In this study, hybrid cycles of the systems are selected for the analysis. In this method, to calculate the rate of endogenous exergy destruction in the kth component, it is set on its real condition, and the other components work on their ideal conditions (with no irreversibilities). The components' ideal conditions selected for this study are shown in Table 2 .

\subsubsection{Avoidable/Unavoidable Exergy Destruction}

Some values of exergy loss rates in each part, which are called unavoidable exergy destruction $\left(\dot{E}_{D . k}^{U N}\right)$, cannot be reduced owing to technical limitations such as accessibility, cost of materials and making.

In order to calculate the unavoidable exergy destruction, some assumptions for the unavoidable conditions of the components are needed, which are usually obtained by researchers' experiences with component operations. In this study, these assumptions are selected from references [12,16,27-29], and these conditions for each component are written in Table 2. To calculate the unavoidable exergy destruction of the kth component, all components are set on their best possible conditions (unavoidable conditions), and the unavoidable loss rates for the kth component are obtained from the equation below [29]:

$$
\dot{E}_{D . k}^{U N}=\dot{E}_{P . k}\left(\frac{\dot{E}_{D . k}}{\dot{E}_{P . k}}\right)^{U N}
$$

Avoidable exergy loss in the kth part is obtained by the subtraction of the unavoidable portion from the exergy loss rate of that part (Equation (23)). The avoidable exergy loss rate is recoverable and can be decreased, so designers should localize this sector to improve system performance.

$$
\dot{E}_{D . k}=\dot{E}_{D . k}^{U N}+\dot{E}_{D . k}^{A V}
$$


Table 2. The assumed conditions for performing an advanced exergy analysis under real, unavoidable and ideal conditions $[12,18,28,30]$.

\begin{tabular}{cccc}
\hline Cycle Component & Real Conditions & Unavoidable Conditions & Ideal Conditions \\
\hline \multirow{2}{*}{ Evaporator } & $\Delta T_{p p}=8{ }^{\circ} \mathrm{C}$ & $\Delta T_{p p}=3{ }^{\circ} \mathrm{C}$ & $\Delta T_{p p}=0{ }^{\circ} \mathrm{C}$ \\
$\Delta p=2 \%$ & $\Delta p=1 \%$ & $\Delta p=0 \%$ \\
\hline Turbine & $\eta_{\text {is.turbine }}=0.8 \%$ & $\eta_{\text {is.turbine }}=0.95 \%$ & $\eta_{\text {is.turbine }}=1 \%$ \\
\hline Condenser & $\Delta T_{p p}=8{ }^{\circ} \mathrm{C}$ & $\Delta T_{p p}=3{ }^{\circ} \mathrm{C}$ & $\Delta T_{p p}=0{ }^{\circ} \mathrm{C}$ \\
& $\Delta p=2 \%$ & $\Delta p=1 \%$ & $\Delta p=0 \%$ \\
\hline Pump & $\eta_{\text {is.pump }}=0.7 \%$ & $\eta_{\text {is.pump }}=0.9 \%$ & $\eta_{\text {is.pump }}=1 \%$ \\
\hline Feed-water heater & $\Delta p=2 \%$ & $\Delta p=1 \%$ & $\Delta p=0 \%$ \\
\hline
\end{tabular}

\subsubsection{Combination of Splitting}

To have more information about the share of each component of a system in total exergy destruction, the two main parts discussed above can be combined. Researchers can use a combination of endogenous or exogenous parts with avoidable or unavoidable parts for a more detailed designing of the systems [30]. By combining the two main splitting parts, the exogenous/unavoidable and the endogenous/unavoidable, the exogenous/avoidable and the endogenous/avoidable rates are obtained. To reach the unavoidable endogenous rate of the kth component, the equation below is used [31,32]:

$$
\dot{E}_{D . k}^{U N . E N}=\dot{E}_{P . k}^{E N}\left(\frac{\dot{E}_{D . k}}{\dot{E}_{P . k}}\right)^{U N}
$$

In this equation, the ratio of exergy loss to exergy of product in this kth component is obtained in unavoidable conditions of the cycle, and the endogenous product exergy is obtained for the kth component when it is in hybrid cycle conditions. The unavoidable exogenous rate for the kth component is obtained from the following equation:

$$
\dot{E}_{D . k}^{U N . E X}=\dot{E}_{D . k}^{U N}-\dot{E}_{D . k}^{U N . E N}
$$

Then, the avoidable endogenous and exogenous parts of the exergy destruction for the kth component can be gained by reducing the unavoidable endogenous and exogenous exergy losses from the endogenous and exogenous exergy losses of that component, respectively.

$$
\begin{aligned}
& \dot{E}_{D \cdot k}^{A V . E N}=\dot{E}_{D \cdot k}^{E N}-\dot{E}_{D \cdot k}^{U N . E N} \\
& \dot{E}_{D . k}^{A V . E X}=\dot{E}_{D . k}^{E X}-\dot{E}_{D . k}^{U N . E N}
\end{aligned}
$$

The real potential of components in a system to improve their performances and to have the best efficiencies in a general system may be determined and analyzed by a mixture of the exergy loss sections mentioned above. There is no way to decrease the unavoidable/endogenous section of exergy loss because of technological limitations of the kth part, while avoidable/endogenous parts of the exergy destruction can be decreased by improving the efficiency of related components. The exogenous/unavoidable part of exergy loss for each component cannot be reduced because of technological constraints associated with other system components. However, the exogenous/avoidable parts may be decreased by the betterment of the total system performance, the efficiency of related components and, also, by improving the performance of other components in a system. 


\section{Simulation, Results and Discussion}

The EES (engineering equation solver) is one of the most commonly used softwares to simulate power cycle operations. In this research, the EES was used to simulate cycle processes and to calculate properties of parameters in a system to reach cycle efficiencies. The input data and parameters for system components' working conditions of waste heat conditions used in this study are obtained from previous studies [12]. The conditions are shown in Table 3. These conditions are used for both conventional and advanced exergy analysis in this research.

Table 3. Heat source parameters and assumptions [12].

\begin{tabular}{cc}
\hline Parameter & Value \\
\hline Temperature of heat source $(\mathrm{K})$ & 420 \\
Mass flow of heat source $\left(\mathrm{kg} \mathrm{s}^{-1}\right)$ & 14 \\
Heat capacity of hot gases in constant pressure $\left(\mathrm{kj} \mathrm{kg}^{-1} \mathrm{~K}^{-1}\right)$ & 1.1 \\
Environmental temperature $(\mathrm{K})$ & 298.15 \\
Environmental pressure $(\mathrm{kPa})$ & 101.35 \\
Temperature of condensing (K) & 303.15 \\
Isentropic efficiency of turbine & 0.8 \\
Isentropic efficiency of pump & 0.7 \\
Minimum temperature difference in the evaporator (Pinch) (K) & 8 \\
\hline
\end{tabular}

\subsection{Model Validation}

For validation, the comparison between the present models and Reference [8] is considered in this section (Table 4). There might be some errors due to the basic equations that EES uses to derive the characteristics of fluids. As results show, the deviation is low, and the models can be used for this analysis.

Table 4. Model validation of simulations by R11 with Reference [8].

\begin{tabular}{ccccccc}
\hline \multirow{2}{*}{ Parameter } & \multicolumn{2}{c}{ BORC Results } & \multicolumn{2}{c}{ SRORC Results } & \multicolumn{2}{c}{ DRORC Results } \\
\cline { 2 - 6 } & This Study & Reference [12] & This Study & Reference [12] & This Study & Reference [12] \\
\hline $\mathrm{T}_{\mathrm{e}}(\mathrm{K})$ & 401.263 & 401.6 & 407.412 & 407.7 & 407.682 & 408 \\
$\mathrm{P}_{3}(\mathrm{kPa})$ & 125.961 & 125.3 & 125.961 & 125.3 & 125.961 & 125.3 \\
$\mathrm{~T}_{\text {out }}(\mathrm{K})$ & 401.930 & 401.4 & 413.312 & 413.5 & 414.104 & 414.6 \\
$\mathrm{e} \eta$ & 50.61 & 58.4 & 55.00 & 63.19 & 56.87 & 65.2 \\
$\eta_{\mathrm{t}}$ & 13.89 & 15.99 & 15.64 & 17.98 & 16.21 & 18.62 \\
$\mathrm{~W}_{\mathrm{p} 1}(\mathrm{~kW})$ & 1.362 & 1.502 & 0.5967 & 0.6251 & 0.496 & 0.5175 \\
$\mathrm{~W}_{\mathrm{p} 2}(\mathrm{~kW})$ & - & - & 0.138 & 0.1457 & 0.128 & 0.1396 \\
$\mathrm{~W}_{\mathrm{p} 3}(\mathrm{~kW})$ & - & - & - & - & 0.074 & 0.07804 \\
$\mathrm{~W}_{\mathrm{t}}(\mathrm{kW})$ & 40.003 & 43.91 & 16.845 & 17.65 & 15.418 & 16.17 \\
$\mathrm{~W}_{\mathrm{net}}(\mathrm{kW})$ & 38.641 & 42.41 & 16.111 & 16.88 & 14.720 & 15.43 \\
$\mathrm{~m}(\mathrm{~kg} / \mathrm{s})$ & 1.215 & 1.17 & 0.568 & 0.5212 & 0.536 & 0.4929 \\
$\mathrm{Q}_{\mathrm{e}}(\mathrm{kj} / \mathrm{s})$ & 278.267 & 265.1 & 102.999 & 96.63 & 90.800 & 91.32 \\
$\mathrm{Q}_{\mathrm{c}}(\mathrm{kj} / \mathrm{s})$ & 239.626 & 222.7 & 86.888 & 93.89 & 76.080 & 82.89 \\
$\mathrm{X}_{\mathrm{c} 1}$ & - & - & 0.20309 & 0.2031 & 0.132 & 0.1323 \\
$\mathrm{X}_{\mathrm{c} 2}$ & - & - & - & - & 0.128 & 0.129 \\
\hline
\end{tabular}

As shown in Table 4, DRORC has a maximum exergy efficiency with $65.2 \%$ among the present systems. BORC produced more power compared with two other cycles, but as it is seen, this system has the lowest exergy efficiency because of its high exergy destruction rate in its components.

\subsection{Conventional and Advanced Exergy Analysis}

Considering conventional exergy analysis and by using the equations for each component of the cycles presented in Table 1, the exergy destruction rates are obtained. In the three cycles, the total exergy 
fuel rate is obtained from subtracting the exergy rate of the working fluid that leaves the evaporator from exhaust gases that enter the evaporator, and the total product exergy is the turbine power output. The main results of the conventional exergy analysis for BORC, SRORC and DRORC are presented in Tables 5-7, respectively. $E_{F}, E_{P}, E_{P}, E_{D}, Y_{K}, Y_{K}^{*}$ in this tables are exergy of fuel, exergy of product, exergy destruction, exergy loss ratio and exergy of fuel with the total exergy destruction. It can be said that the components with higher exergy destruction rates have more effects on the efficiency of systems from an exergy point of view compared with other components. Referring to Table 5, in BORC, the maximum exergy destruction rate happens in the evaporator, followed by the turbine, the condenser and the pump. Table 6 shows the exergy destruction rates for the SRORC components. As it is seen, in single-regenerative systems, turbines show the highest exergy destruction rates among cycles components due to their design, and evaporators, condensers, feed-water heaters and pumps are in the next ranks, respectively. For DRORC, the exergy destructive rates are shown in Table 7 . In these systems, as in single-regenerative cycles, turbines have the maximum exergy destructive rate, and they are followed by evaporators. However, unlike SRORC, pump1 and feed-water heater 2 are placed in the next ranks because of the second flow that extracts from the turbine. As a summary, it can be concluded that evaporators, turbines and feed-waters have more potential to reduce their destructive rates and to increase system efficiency. As it is seen, a conventional exergy analysis just focuses on components with high rates of exergy destruction, and it is not possible to specify whether these destructions occur in other components or in the component itself. These irreversibilities may only be specified by advanced exergy tools. As discussed above, an advanced exergy analysis evaluates the effects of component interactions and the real possibility of components to improve system efficiency.

Table 5. Results from exergy calculations for BORC.

\begin{tabular}{ccccccc}
\hline Component & $E_{\boldsymbol{F}}(\mathbf{k W})$ & $E_{\boldsymbol{P}}(\mathbf{k W})$ & $E_{\boldsymbol{D}}(\mathbf{k W})$ & $\varepsilon \mathbf{( \% )}$ & $\boldsymbol{Y}_{\boldsymbol{K}}(\mathbf{\%})$ & $\boldsymbol{Y}_{\boldsymbol{K}}^{*}(\mathbf{\%})$ \\
\hline Evaporator & 88.95 & 74.51 & 14.44 & 83.766 & 16.233 & 46.898 \\
Turbine & 53.1 & 43.68 & 9.42 & 82.259 & 17.740 & 30.594 \\
Pump & 1.538 & 1.538 & 0 & 100 & 0 & 0 \\
Condenser & 22.94 & 16.01 & 6.93 & 69.790 & 30.209 & 22.507 \\
\hline
\end{tabular}

Table 6. Results from exergy calculations for SRORC.

\begin{tabular}{ccccccc}
\hline Component & $\boldsymbol{E}_{\boldsymbol{F}}(\mathbf{k W})$ & $\boldsymbol{E}_{\boldsymbol{P}}(\mathbf{k W})$ & $\boldsymbol{E}_{\boldsymbol{D}}(\mathbf{k W})$ & $\varepsilon \mathbf{( \% )}$ & $\boldsymbol{Y}_{\boldsymbol{K}}(\mathbf{\%})$ & $\boldsymbol{Y}_{\boldsymbol{K}}^{*}(\mathbf{\%})$ \\
\hline Evaporator & 32.63 & 30.16 & 2.47 & 92.430 & 7.569 & 28.036 \\
Turbine & 21.5 & 17.64 & 3.86 & 82.046 & 17.953 & 43.813 \\
Pump1 & 0.648 & 0.148 & 0.499 & 22.962 & 77.037 & 5.666 \\
Pump2 & 0.151 & 0.015 & 0.135 & 10.257 & 89.742 & 1.541 \\
Feed-water heater & 4.778 & 3.84 & 0.938 & 80.368 & 19.631 & 10.647 \\
Condenser & 7.887 & 6.98 & 0.907 & 88.500 & 11.499 & 10.295 \\
\hline
\end{tabular}

Table 7. Results from exergy calculations for DRORC.

\begin{tabular}{ccccccc}
\hline Component & $\boldsymbol{E}_{\boldsymbol{F}} \mathbf{( k W )}$ & $\boldsymbol{E}_{\boldsymbol{P}} \mathbf{( k W )}$ & $\boldsymbol{E}_{\boldsymbol{D}} \mathbf{( k W )}$ & $\mathcal{\varepsilon} \mathbf{( \% )}$ & $\boldsymbol{Y}_{\boldsymbol{K}} \mathbf{( \% )}$ & $\boldsymbol{Y}_{\boldsymbol{K}}^{*} \mathbf{( \% )}$ \\
\hline Evaporator & 28.67 & 26.91 & 1.76 & 93.861 & 6.138 & 15.087 \\
Turbine & 24.39 & 16.06 & 8.33 & 65.846 & 34.153 & 71.408 \\
Pump1 & 0.536 & 0.138 & 0.397 & 25.857 & 74.142 & 3.409 \\
Pump2 & 0.145 & 0.028 & 0.116 & 19.545 & 80.454 & 1.001 \\
Pump 3 & 0.079 & 0.008 & 0.0717 & 10.232 & 89.767 & 0.615 \\
Feed-water heater1 & 3.274 & 3.044 & 0.23 & 92.974 & 7.025 & 1.971 \\
Feed-water heater2 & 2.421 & 1.984 & 0.437 & 81.949 & 18.050 & 3.746 \\
Condenser & 6.867 & 6.545 & 0.322 & 95.310 & 4.689 & 2.760 \\
\hline
\end{tabular}

By advanced exergy analysis, the exergy destructions of each component calculated in the previous section can be discussed in detail to find the sources of these destructions and real potentials of each component to amend the efficiency of the whole system. As mentioned above, these irreversibilities 
can be divided into exogenous, endogenous, unavoidable and avoidable parts to help researchers observe the effects of technological limitations and component interactions on the exergetic efficiency of a system for improvements [33]. In the advanced exergy analysis, the endogenous part of exergy loss for the kth component is calculated by defining real and ideal conditions for the cycles first. Then, the exogenous destruction rate is obtained by the difference of the total exergy and endogenous part (Equation (22)). To calculate the unavoidable exergy rate of loss in the kth part, instead of real conditions in cycles, unavoidable conditions are considered, and avoidable exergy is obtained from Equation (23). Furthermore, the values of exogenous/avoidable, endogenous/avoidable, exogenous/unavoidable and endogenous/unavoidable are determined using Equations (25) to (28). Advanced exergy analysis results for each part in three different cycles (BORC, SRORC and DRORC) are presented in Tables 8-10.

Table 8. Advanced exergy analysis results $(\mathrm{kW})$ for BORC.

\begin{tabular}{cccccccccc}
\hline Component & $\dot{E}_{\boldsymbol{D}}$ & $\dot{E}_{\boldsymbol{D}}^{U N}$ & $\dot{E}_{\boldsymbol{D}}^{A V}$ & $\dot{E}_{\boldsymbol{D}}^{E N}$ & $\dot{E}_{\boldsymbol{D}}^{E X}$ & $\dot{E}_{\boldsymbol{D}}^{A V . E X}$ & $\dot{E}_{D}^{A V . E N}$ & $\dot{E}_{D}^{\text {UN.EX }}$ & $\dot{E}_{\boldsymbol{D}}^{\text {UN.EN }}$ \\
\hline Evaporator & 14.44 & 7.725 & 6.714 & 14.13 & 0.31 & 0.357 & 6.356 & -0.047 & 7.773 \\
Turbine & 9.42 & 2.0194 & 7.400 & 3.135 & 6.285 & 4.935 & 2.464 & 1.349 & 0.670 \\
Pump & 0 & 0 & 0 & 0 & 0 & 0 & 0 & 0 & 0 \\
Condenser & 6.93 & 4.168 & 2.761 & 2.06 & 4.87 & 2.005 & 0.756 & 2.864 & 1.303 \\
\hline
\end{tabular}

Table 9. Advanced exergy analysis results $(\mathrm{kW})$ for SRORC.

\begin{tabular}{|c|c|c|c|c|c|c|c|c|c|}
\hline Component & $\dot{E}_{D}$ & $\dot{E}_{D}^{U N}$ & $\dot{E}_{D}^{A V}$ & $\dot{E}_{D}^{E N}$ & $\dot{E}_{D}^{E X}$ & $\dot{E}_{D}^{A V . E X}$ & $\dot{E}_{D}^{A V . E N}$ & $\dot{E}_{D}^{U N . E X}$ & $\dot{E}_{D}^{U N . E N}$ \\
\hline Evaporator & 2.47 & 1.027 & 1.442 & 2.561 & -0.091 & -0.084 & 1.527 & -0.006 & 1.033 \\
\hline Turbine & 3.86 & 0.824 & 3.035 & 2.083 & 1.777 & 1.397 & 1.637 & 0.379 & 0.445 \\
\hline Pump 1 & 0.499 & 0.067 & 0.431 & 0.263 & 0.235 & 0.203 & 0.228 & 0.032 & 0.034 \\
\hline Pump 2 & 0.135 & 0.014 & 0.121 & 0.067 & 0.067 & 0.060 & 0.060 & 0.007 & 0.007 \\
\hline Feed-water heater & 0.938 & 0.299 & 0.638 & 0.479 & 0.458 & 0.313 & 0.324 & 0.144 & 0.155 \\
\hline Condenser & 0.907 & 0.168 & 0.738 & 0.441 & 0.465 & 0.382 & 0.356 & 0.082 & 0.085 \\
\hline
\end{tabular}

Table 10. The results of the advanced exergy analysis (per $\mathrm{kW}$ ) for DRORC.

\begin{tabular}{cccccccccc}
\hline Component & $\dot{E}_{\boldsymbol{D}}$ & $\dot{\boldsymbol{E}}_{\boldsymbol{D}}^{U N}$ & $\dot{\boldsymbol{E}}_{\boldsymbol{D}}^{A V}$ & $\dot{\boldsymbol{E}}_{\boldsymbol{D}}^{E N}$ & $\dot{\boldsymbol{E}}_{\boldsymbol{D}}^{E X}$ & $\dot{\boldsymbol{E}}_{\boldsymbol{D}}^{A V . E X}$ & $\dot{\boldsymbol{E}}_{\boldsymbol{D}}^{A V . E N}$ & $\dot{\boldsymbol{E}}_{\boldsymbol{D}}^{\text {UN.EX }}$ & $\dot{\boldsymbol{E}}_{\boldsymbol{D}}^{\text {UN.EN }}$ \\
\hline Evaporator & 1.76 & 0.463 & 1.296 & 1.845 & -0.085 & -0.080 & 1.377 & -0.004 & 0.467 \\
Turbine & 8.33 & 1.742 & 6.587 & 4.188 & 4.142 & 3.284 & 3.303 & 0.857 & 0.884 \\
Pump 1 & 0.397 & 0.064 & 0.333 & 0.199 & 0.198 & 0.165 & 0.167 & 0.032 & 0.031 \\
Pump 2 & 0.116 & 0.018 & 0.098 & 0.054 & 0.062 & 0.053 & 0.045 & 0.009 & 0.008 \\
Pump 3 & 0.071 & 0.006 & 0.065 & 0.033 & 0.038 & 0.035 & 0.030 & 0.003 & 0.003 \\
Feed-water heater 1 & 0.23 & 0.080 & 0.149 & 0.113 & 0.116 & 0.075 & 0.074 & 0.041 & 0.039 \\
Feed-water heater 2 & 0.437 & 0.124 & 0.312 & 0.205 & 0.231 & 0.167 & 0.146 & 0.064 & 0.059 \\
Condenser & 0.322 & 0.072 & 0.249 & 0.138 & 0.183 & 0.145 & 0.104 & 0.038 & 0.034 \\
\hline
\end{tabular}

As indicated in Table 9, for BORC, the exogenous exergy rate is greater than the endogenous exergy rate in system components, except the evaporator. So, system performance and modification of other components are necessary for turbines and condensers to decrease their exogenous destruction rates. The greater share of exergy destruction in the evaporator is caused by irreversibility of the component itself because of its high exergy loss rate in the endogenous part. As it was discussed before, the avoidable destruction rate in exergy can be controlled and reduced in practice. Table 8 shows that a turbine consists of a high value of avoidable destruction rates $(7.4 \mathrm{~kW})$ among the components of a system. Thus, the efficiency of this component can be improved using some technical modifications and new technologies or by replacing the component with the ones with higher efficiencies. It is important to note that, unlike the conventional analysis, a turbine is the most effective component due to its avoidable destruction rate to reduce irreversibilities. So, the main focus will be on the avoidable/endogenous parts of the exergy destruction, which can be decreased by improving the efficiency of the kth component. It follows by an investigation on the exogenous/avoidable exergy rates of loss, which can be reduced by improving the efficiency of other parts [34]. As it is stated 
in [17], Table 8 shows that the avoidable/endogenous exergy destruction rates in the turbine are greater than the unavoidable/endogenous destruction rates for BORC. This shows that the efficiency can be improved by technical modifications of this component. Table 8 also indicates that, except the condenser, the exogenous/avoidable exergy destruction rates are higher than the exogenous/unavoidable exergy rates of loss for the components. Results of the advanced exergy analysis for the division of the exergy rate of loss in the main parts in BORC are shown in Figure 4. As Figure 4 indicates, for the turbine, 79\% of the total exergy rate of loss is avoidable, and from this rate, $53 \%$ can be reduced by amending other components efficiencies, and $26 \%$ of this rate depends on the performance of the component itself.

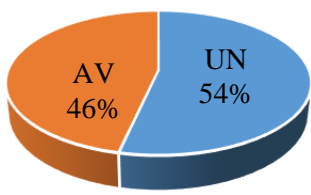

(a)

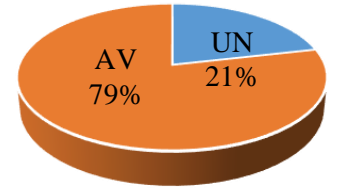

(b)

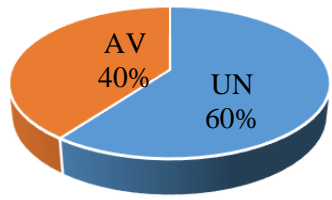

(c)
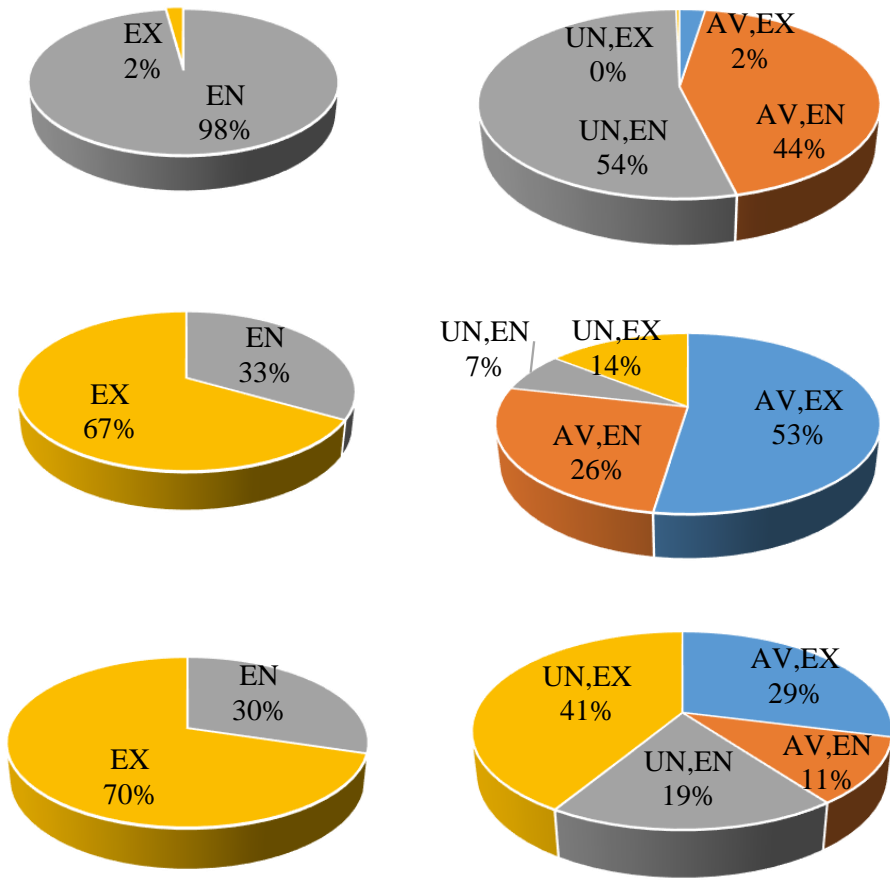

Figure 4. Splitting exergy destruction rates of components: (a) the evaporator, (b) turbine and (c) condenser in the BORC system.

In Table 9, for SRORC, except the condenser, the endogenous exergy destruction rate is higher than the exogenous exergy destruction rate in the system's components, which shows that, unlike BORC, the greater share of the destruction rate is because of the internal irreversibilities in the component itself. So, among all components in SRORC, the turbine consists of the highest destruction rate in the exogenous part $(1.77 \mathrm{~kW})$, and the evaporator has the maximum endogenous destruction rate $(2.56 \mathrm{~kW})$ among the system's components due to its irreversibilities. As it is seen in Table 9, the avoidable part of the exergy destruction rate is higher than the unavoidable part in all components of SRORC. This indicates that there is a great potential in a system to reduce its irreversibilities by using some efficient and new components. Splitting the exergy destruction rates into endogenous/avoidable and exogenous/avoidable parts provides some important information that helps researchers to optimize systems. As it is seen in Table 9, the avoidable/endogenous exergy destruction rates in all equipment are higher than the exogenous/avoidable rates, except for the condenser. Priority in the improvement process of a component should be given to the turbine and the evaporator because of their higher values in the endogenous/avoidable destruction rates. For a better analysis, results for splitting the exergy destruction rate for the components in SRORC are shown in Figure 5. The highest unavoidable/endogenous exergy destruction rates belong to the evaporator in the system, with about a $54 \%$ of the total exergy destruction rate, which shows low potential in reducing the irreversibility for this component. 


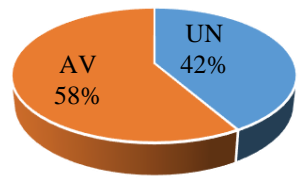

(a)

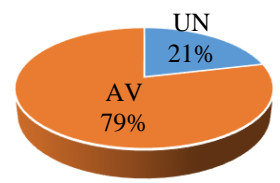

(b)

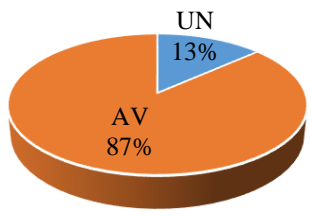

(c)

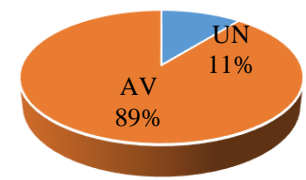

(d)

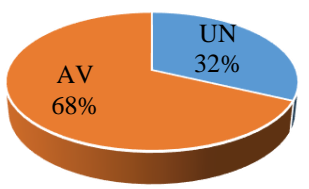

(e)

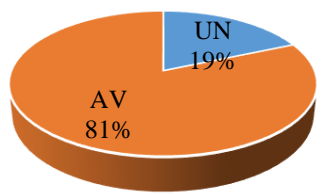

(f)
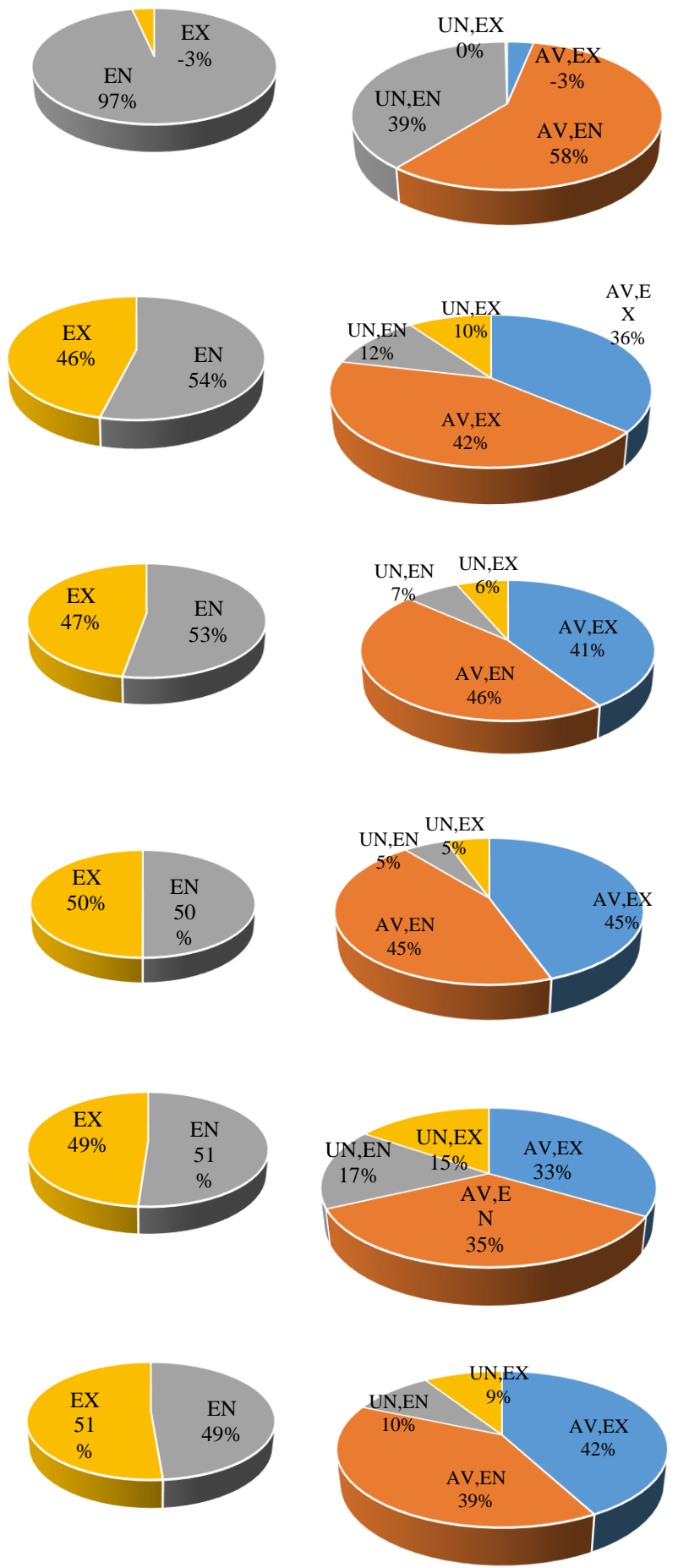

Figure 5. Splitting exergy destruction rates of components: (a) the evaporator, (b) turbine, (c) pump1, (d) pump2, (e) feed-water heater and (f) condenser in the SRORC system.

By referring to Table 10, it can be seen that, for DRORC, the endogenous exergy rate of loss is higher than the exogenous part for the evaporator and the turbine. This means that, in order to reduce the destruction rate, designers should focus on improving the efficiency of these components. Additionally, from these results, it is observed that there is a considerable contribution of the exergy rate of loss in pumps, feed-water heaters and condensers because of other components' performances in the systems. As it is mentioned above, the avoidable exergy destruction rate is an important part in reducing destruction. Table 10 shows that the avoidable exergy destruction rate is higher than the 
unavoidable part for all components in DRORC, which indicates that a system has a great potential for reducing its total exergy destruction by using modern technologies or replacing components with new, efficient ones. Among components, turbines with $6.587 \mathrm{~kW}$ consist of the highest avoidable exergy destruction rate, which should be paid more attention to in designing. As it is shown in Table 10, the endogenous/avoidable exergy destruction rates for the evaporator, turbine and pump1 is higher than the endogenous/unavoidable destruction rates in DRORC. Modifications in these components and improving working conditions should be noticed by designers to reduce this part of the exergy destruction. Priority in improving the performance of components in DRORC should be given to the turbine, the evaporator, pump 1 and feed-water heater 2 . As for the previous cycles, the results of the advanced exergy analysis for DRORC components are shown in Figure 6.

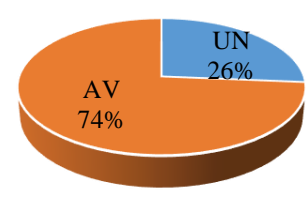

(a)

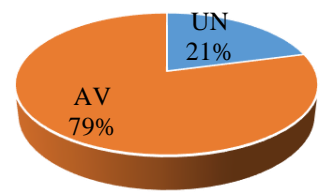

(b)

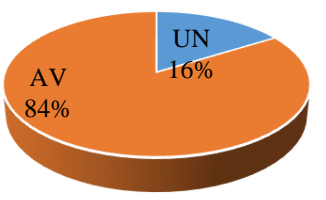

(c)
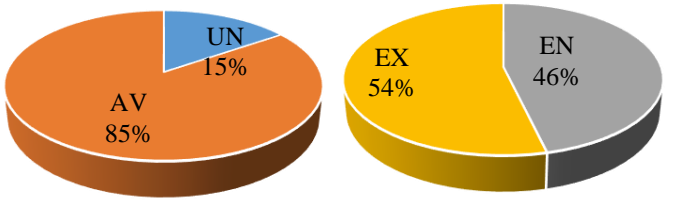

(d)
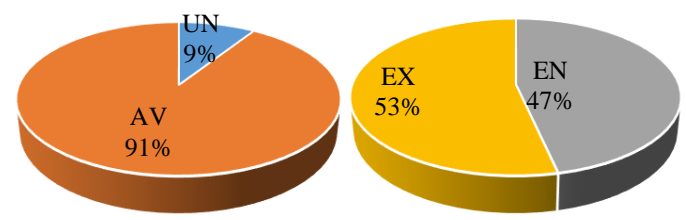

(e)

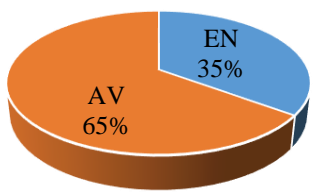

(f)
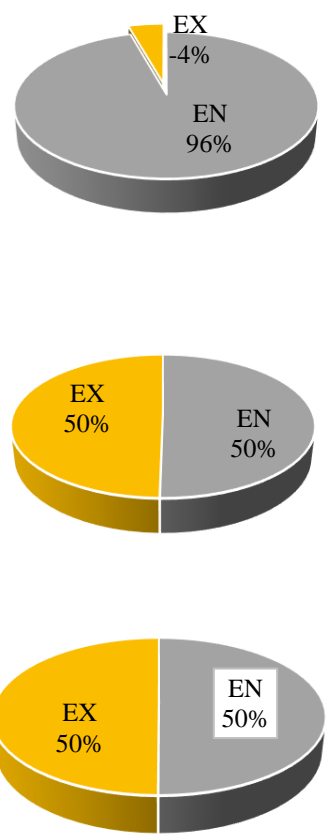
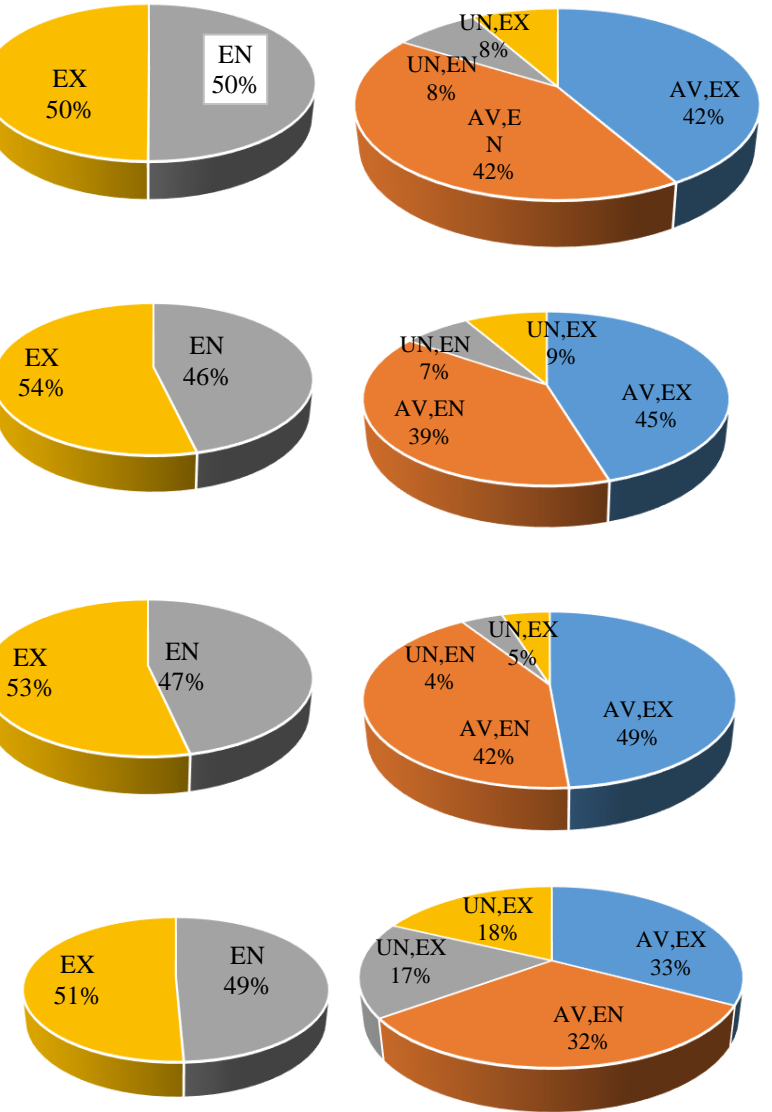

Figure 6. Cont. 


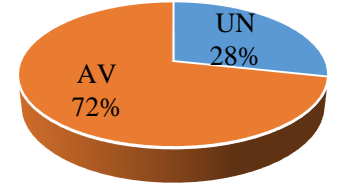

(g)

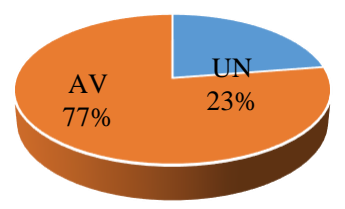

(h)
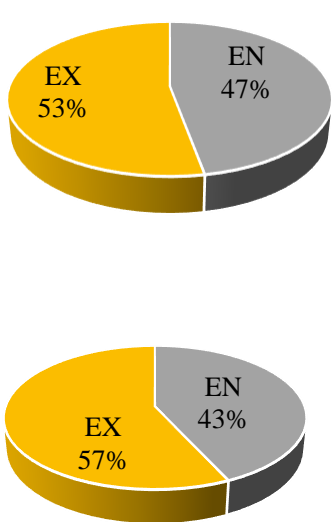
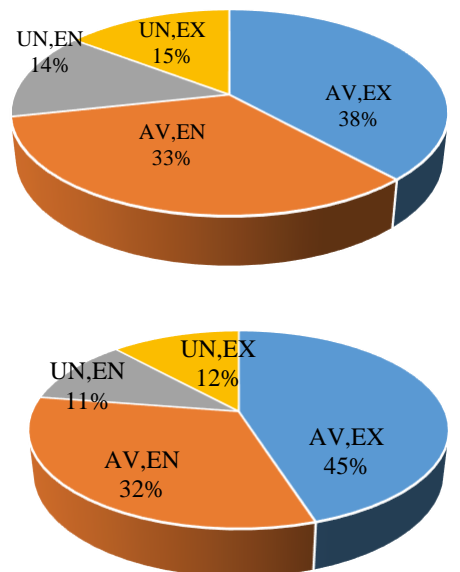

Figure 6. Splitting exergy destruction rates of components: (a) the evaporator, (b) turbine, (c) pump1, (d) pump2, (e) pump3, (f) feed-water heater1, (g) feed-water heater 2 and (h) condenser in the DRORC system.

In addition, the total exergy destruction rate for different parts obtained from an advanced exergy analysis for the three cycles are shown in Figures 7-9. As indicated, the total avoidable exergy rate of loss in these three systems is higher than unavoidable part, which shows a good potential to reduce irreversibilities. Avoidable exergy rate of loss with about $78 \%$ of the total rate of loss in DRORC is the first to be noticed by designers. SRORC and BORC with $74 \%$ and $55 \%$, respectively, are given the next priorities. Additionally, in SRORC and DRORC, the total endogenous/avoidable exergy destruction rates are about $47 \%$ and $45 \%$ of the total exergy destruction rate, respectively, which are higher than other three combination parts.

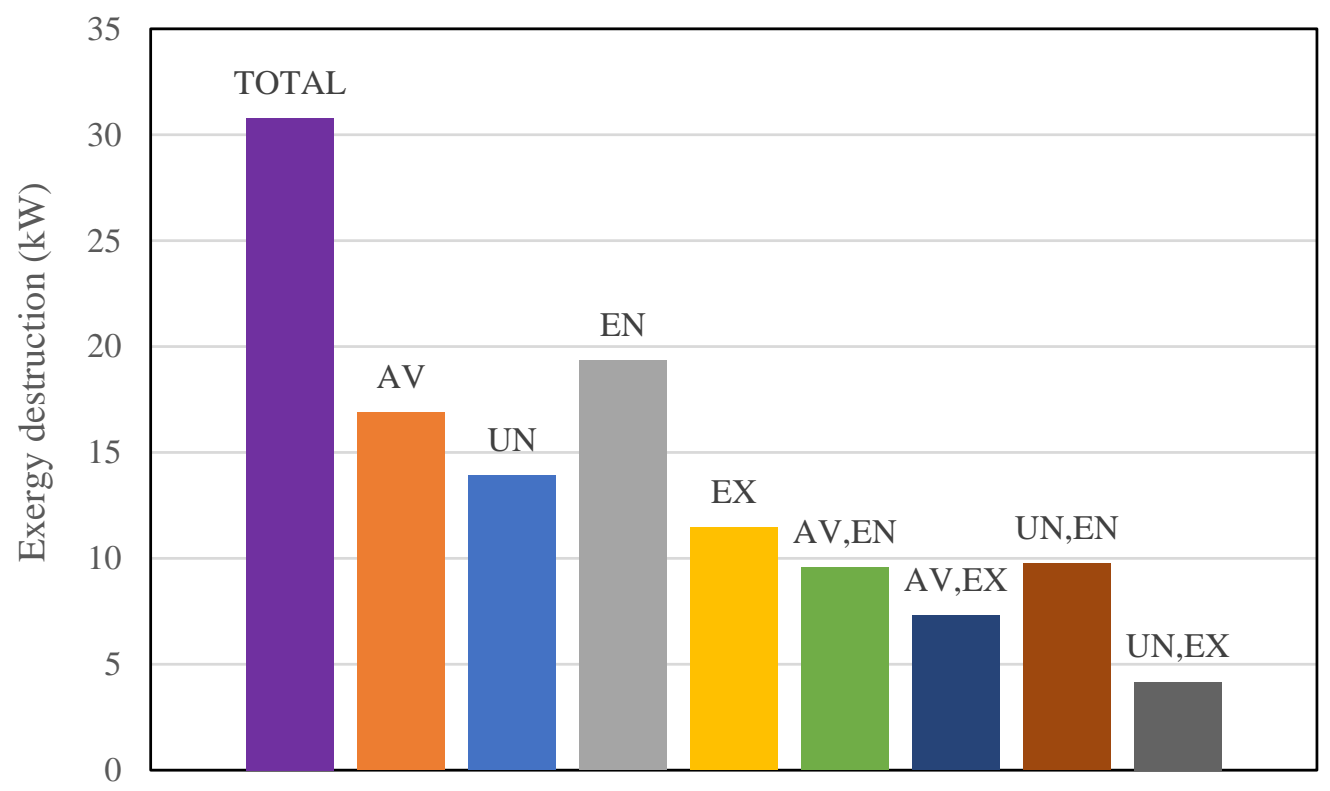

Figure 7. Total exergy destruction rate for the different parts in BORC. 


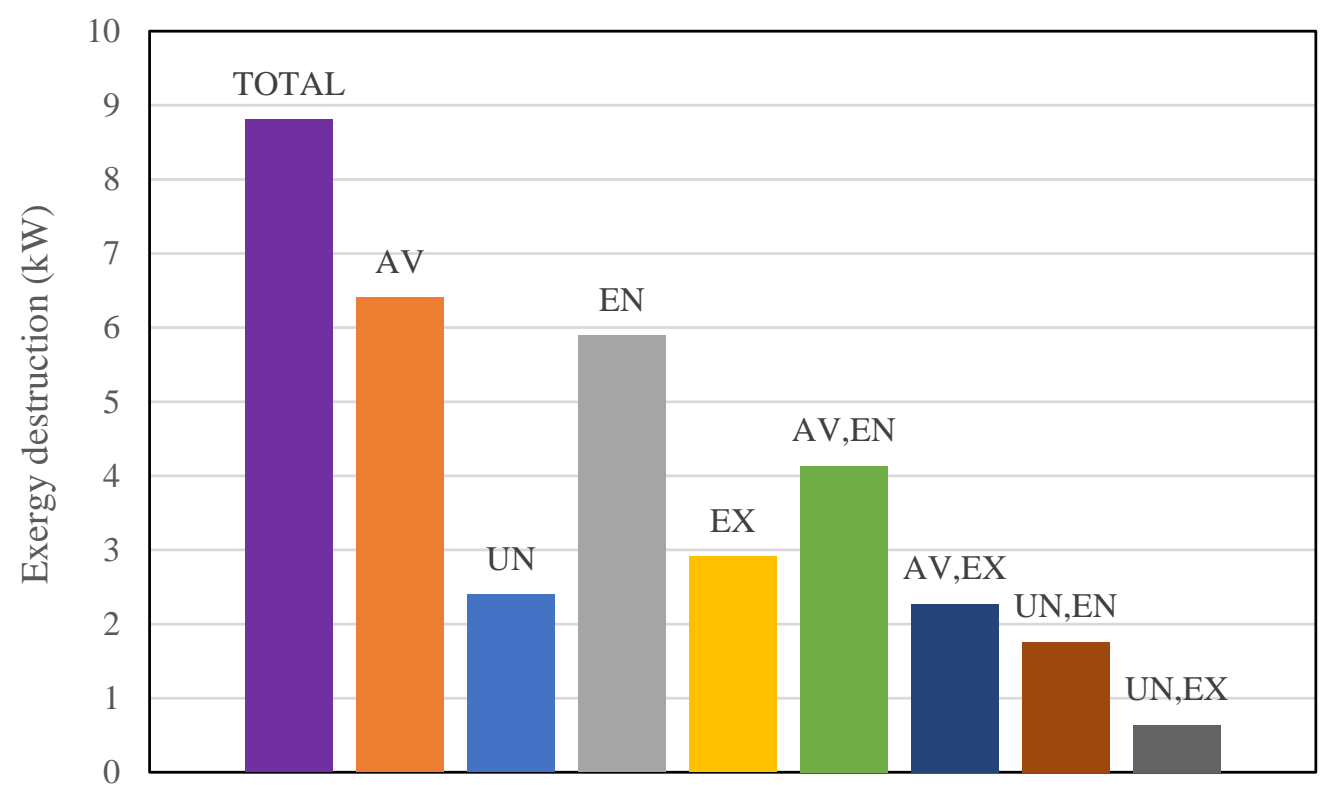

Figure 8. Total exergy destruction rate for the different parts in single-regeneration ORC (SRORC).

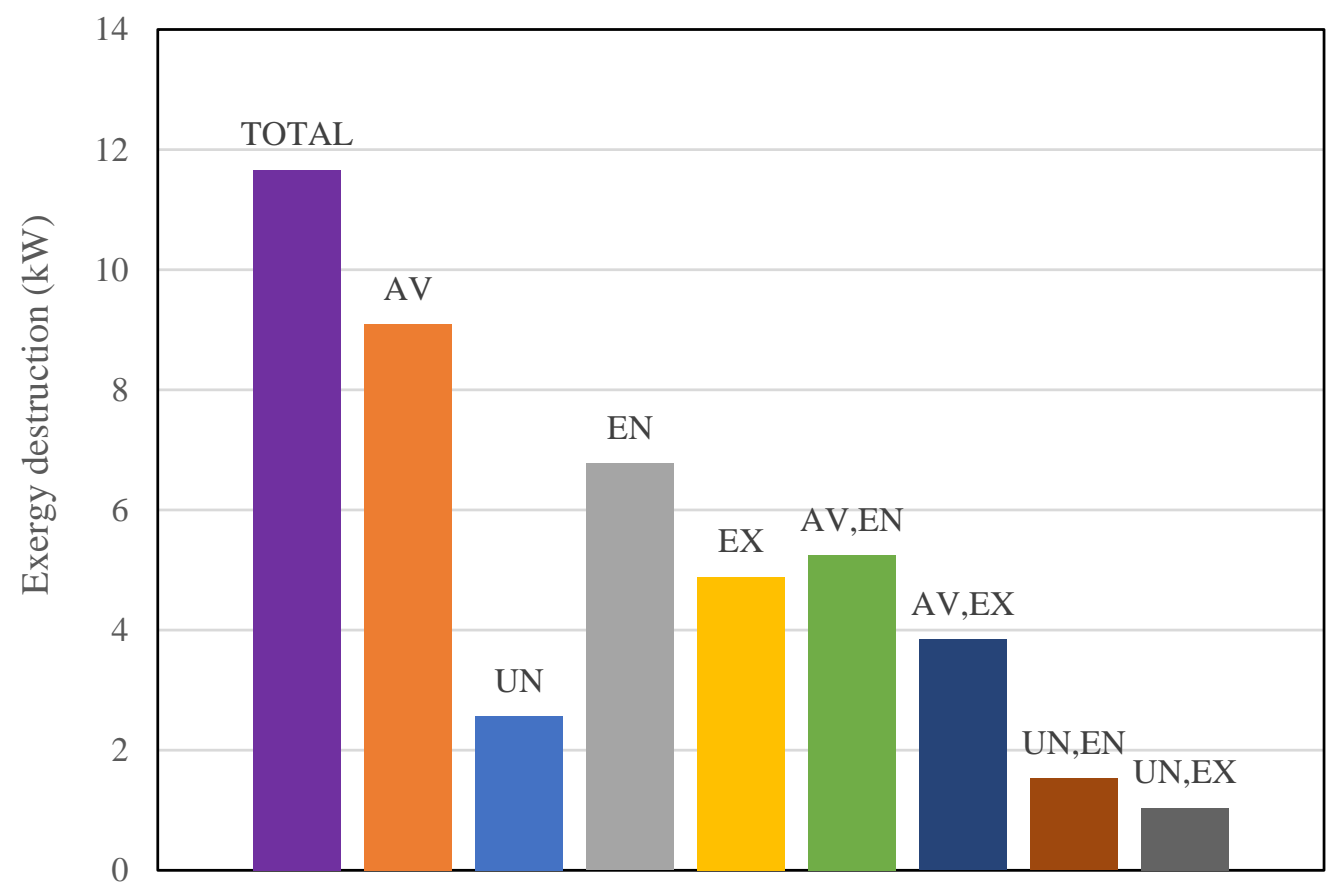

Figure 9. Total exergy destruction rate for the different parts in DRORC.

\section{Conclusions}

In this research, conventional and advanced exergy analysis are performed for three different models of organic Rankine cycles (BORC, SRORC and DRORC) at specified operating conditions by the use of a low-temperature heat source. The main results obtained from the present study are listed as below:

- According to the conventional exergy analysis, the highest exergy destruction was obtained in the evaporator for BORC, and for SRORC and DRORC, the maximum exergy destruction belongs to the turbine. Additionally, results of the conventional exergy analysis show that the condenser in 
three cycles is the third important component that should be noticed in designing. The exergy destruction rate for pumps may be neglected.

- The advanced exergy analysis showed that the exogenous exergy destruction rate is greater than the endogenous exergy destruction rate, except the evaporator, for BORC. However, in SRORC, the endogenous exergy rate of loss is higher than the exogenous part, except for the condenser. This indicates the greater share of the exergy destruction rate because of the internal irreversibilities in the component itself compared with BORC. Avoidable rate of exergy destruction in BORC, SRORC and DRORC are about $78 \%, 74 \%$ and $55 \%$ of the total destruction rate, respectively. Among the existing components, the condenser has the maximum value of exogenous exergy destruction rate, which can be reduced by the modification of other components.

- The endogenous/avoidable exergy destruction was identified as an important part of the destruction. Thirty-one percent, forty-seven percent and forty-five percent of the total exergy destruction rate in BORC, SRORC and DRORC placed in this part, respectively, can be reduced by improving the efficiency of the components.

- By the advanced exergy analysis, unlike the conventional exergy analysis, the preference of improvement should be given to turbines, evaporators, condensers and feed-water heaters, respectively. Additionally, regenerative cycles have high potentials to reduce their irreversibilities compared with basic systems.

Author Contributions: S.Y.D.; conceptualization; methodology; software; validation; formal analysis; writing—original draft preparation. G.S.; writing—original draft preparation; writing—review and editing; visualization; supervision. A.D.; writing-review and editing; supervision. All authors have read and agreed to the published version of the manuscript.

Funding: This research received no external funding.

Conflicts of Interest: The authors declare no conflicts of interest.

$\begin{array}{ll}\text { Nomenclature } \\ \text { parameter } & \text { define } \\ \text { ORCs } & \text { Organic Rankin cycles } \\ \text { BORC } & \text { Basic organic Rankin cycles } \\ \text { SRORC } & \text { Single regeneration organic Rankin cycles } \\ \text { DRORC } & \text { Double regeneration organic Rankin cycles } \\ \text { M } & \text { Mass flow rate } \\ \text { E } & \text { exergy } \\ \text { Eph } & \text { physical exergy } \\ \text { Ech } & \text { Chemical exergy } \\ \eta & \text { energy efficiency } \\ \varepsilon & \text { exergy efficiency } \\ E_{F} & \text { exergy of fuel } \\ E_{P} & \text { exergy of product } \\ E_{D} & \text { exergy destruction } \\ Y_{K} & \text { exergy loss ratio with the total exergy destruction } \\ Y_{K}^{*} & \text { exergy of fuel with the total exergy destruction } \\ \dot{E}_{D}^{A V} & \text { avoidable exergy destruction } \\ \dot{E}_{D}^{E N} & \text { endogenous exergy destruction } \\ \dot{E}_{D}^{E X} & \text { exogenous exergy destruction } \\ \dot{E}_{D}^{U N} & \text { unavoidable exergy destruction } \\ \dot{E}_{D}^{U N . E N} & \text { unavoidable endogenous exergy destruction } \\ \dot{E}_{D}^{A V . E N} & \text { avoidable endogenous exergy destruction } \\ \dot{E}_{D}^{A V . E X} & \text { avoidable exogenous exergy destruction } \\ & \end{array}$




\section{References}

1. Yamamoto, T.; Furuhata, T.; Arai, N.; Mori, K. Design and testing of the organic Rankine cycle. Energy 2001, 26, 239-251. [CrossRef]

2. Bao, J.; Zhao, L. A review of working fluid and expander selections for Organic Rankine Cycle. Renew. Sustain. Energy Rev. 2013, 24, 325-342. [CrossRef]

3. Lecompte, S.; Huisseune, H.; Van Den Broek, M.; Vanslambrouck, B.; De Paepe, M. Review of organic Rankine cycle (ORC) architectures for waste heat recovery. Renew. Sustain. Energy Rev. 2015, 47, 448-461. [CrossRef]

4. Zhang, S.J.; Wang, H.X.; Guo, T. Performance comparison and parametric optimization of subcritical organic Rankine cycle (ORC) and transcritical power cycle system for low-temperature geothermal power generation. Appl. Energy 2011, 88, 2740-2754.

5. Li, J.; Pei, G.; Ji, J. Optimization of low temperature solar thermal electric generation with organic Rankine cycle in different areas. Appl. Energy 2010, 87, 3355-3365.

6. Davarpanah, A. Feasible analysis of reusing flowback produced water in the operational performances of oil reservoirs. Environ. Sci. Pollut. Res. 2018, 25, 35387-35395. [CrossRef]

7. Davarpanah, A.; Mirshekari, B. Experimental study of $\mathrm{CO}_{2}$ solubility on the oil recovery enhancement of heavy oil reservoirs. J. Therm. Anal. Calorim. 2019. [CrossRef]

8. Davarpanah, A.; Mirshekari, B. Experimental Investigation and Mathematical Modeling of Gas Diffusivity by Carbon Dioxide and Methane Kinetic Adsorption. Ind. Eng. Chem. Res. 2019. [CrossRef]

9. Davarpanah, A.; Zarei, M.; Valizadeh, K.; Mirshekari, B. CFD design and simulation of ethylene dichloride (EDC) thermal cracking reactor. Energy Sour. Part A Recovery Util. Environ. Eff. 2018, 1-15. [CrossRef]

10. Tchanche, B.F.; Lambrinos, G.; Frangoudakis, A.; Papadakis, G. Low-grade heat conversion into power using Organic Rankine Cycles-A review of various applications. Renew. Sustai.n Energy Rev. 2011, 15, 3963-3979. [CrossRef]

11. El-Emam, R.S.; Dincer, I. Exergy and exergoeconomic analyses and optimization of geothermal organic Rankine cycle. Appl. Therm. Eng. 2013, 59, 435-444. [CrossRef]

12. Xi, H.; Li, M.-J.; He, Y.-L. Parametric optimization of regenerative organic Rankine cycle (ORC) for low grade waste heat recovery using genetic algorithm. Energy 2013, 58, 473-482. [CrossRef]

13. Roy, J.P.; Misra, A. Parametric optimization and performance analysis of a regenerative Organic Rankine Cycle using R-123 for waste heat recovery. Energy 2012, 39, 227-235. [CrossRef]

14. Rashidi, M.M.; Galanis, N.; Nazari, F.; Basiri, P.; Shamekhi, L. Parametric analysis and optimization of regenerative Clausius and Organic Rankine Cycles with two feed-water heaters using artificial bees colony and artificial neural network. Energy 2011, 36, 5728-5740. [CrossRef]

15. Vatani, A.; Mehrpooya, M.; Palizdar, A. Advanced exergetic analysis of five natural gas liquefaction processes. Energy Convers. Manag. 2014, 78, 720-737. [CrossRef]

16. Fallah, M.; Siyahi, H.; Akbarpour Ghiasi, R.; Mahmoudi, S.M.S.; Yari, M.; Rosen, M.A. Comparison of different gas turbine cycles and advanced exergy analysis of the most effective. Energy 2016, 116, 701-715. [CrossRef]

17. Galindo, J.; Ruiz, S.; Dolz, V.; Royo-Pascual, L. Advanced exergy analysis for a bottoming organic rankine cycle coupled to an internal combustion engine. Energy Convers. Manag. 2016, 126, 217-227. [CrossRef]

18. Nami, H.; Nemati, A.; Jabbari Fard, F. Conventional and advanced exergy analyses of a geothermal driven dual fluid organic Rankine cycle (ORC). Appl. Therm. Eng. 2017, 122, 59-70. [CrossRef]

19. Imran, M.; Park, B.-S.; Kim, H.-J.; Lee, D.-H.; Usman, M.; Heo, M. Thermo-economic optimization of Regenerative Organic Rankine Cycle for waste heat recovery applications. Energy Convers. Manag. 2014, 87, 107-118. [CrossRef]

20. Anvari, S.; Taghavifar, H.; Parvishi, A. Thermo-economical consideration of Regenerative organic Rankine cycle coupling with the absorption chiller systems incorporated in the trigeneration system. Energy Convers. Manag. 2017, 148, 317-329. [CrossRef]

21. Hajabdollahi, H.; Ganjehkaviri, A.; Nazri Mohd Jaafar, M. Thermo-economic optimization of RSORC (regenerative solar organic Rankine cycle) considering hourly analysis. Energy 2015, 87, 369-380. [CrossRef]

22. Baccioli, A.; Antonelli, M.; Desideri, U. Technical and economic analysis of organic flash regenerative cycles (OFRCs) for low temperature waste heat recovery. Appl. Energy 2017, 199, 69-87. [CrossRef] 
23. Chen, H.; Goswami, D.-Y.; Stefanakos, E.-K. A review of thermodynamic cycles and working fluids for the conversion of low-grade heat. Renew. Sustain. Energy Rev. 2010, 14, 3059-3067. [CrossRef]

24. Kotas, T.-J. The Exergy Method of Thermal Plant; Anchor Brendon: London, UK, 1985.

25. Wang, S.; Zhang, W.; Feng, Y.-Q.; Wang, X.; Wang, Q.; Liu, Y.-Z.; Wang, Y.; Yao, L. Entropy, Entransy and Exergy Analysis of a Dual-Loop Organic Rankine Cycle (DORC) Using Mixture Working Fluids for Engine Waste Heat Recovery. Energies 2020, 13, 1301. [CrossRef]

26. Khosravi, H.; Salehi, G.R.; Azad, M.T. Design of structure and optimization of organic Rankine cycle for heat recovery from gas turbine: The use of $4 \mathrm{E}$, advanced exergy and advanced exergoeconomic analysis. Appl. Therm. Eng. 2019, 147, 272-290. [CrossRef]

27. Kelly, S.; Tsatsaronis, G.; Morosuk, T. Advanced exergetic analysis: Approaches for splitting the exergy destruction into endogenous and exogenous parts. Energy 2009, 34, 384-391. [CrossRef]

28. Rodríguez, C.E.; Palacio, J.C.; Venturini, O.J.; Lora, E.E.; Cobas, V.M.; Dos Santos, D.M.; Dotto, F.R.; Gialluca, V. Exergetic and economic comparison of ORC and Kalina cycle for low temperature enhanced geothermal system in Brazil. Appl. Therm. Eng. 2013, 52, 109-119. [CrossRef]

29. Petrakopoulou, F. Comparative Evaluation of Power Plants with $\mathrm{CO}_{2}$ Capture: Thermodynamic, Economic and Environmental Performance. Ph.D. Thesis, Technische Universität Berlin, Berlin, Germany, 2011. [CrossRef]

30. Zare, V. A comparative exergoeconomic analysis of different ORC configurations for binary geothermal power plants. Energy Convers. Manag. 2015, 105, 127-138. [CrossRef]

31. Tsatsaronis, G.; Park, M. On avoidable and unavoidable exergy destructions and investment costs in thermal systems. Energy Convers. Manag. 2002, 43, 1259-1270. [CrossRef]

32. Fallah, M.; Mahmoudi, S.M.S.; Yari, M.; Ghiasi, R.A. Advanced exergy analysis of the Kalina cycle applied for low temperature enhanced geothermal system. Energy Convers. Manag. 2016, 108, 190-201. [CrossRef]

33. Petrakopoulou, F.; Tsatsaronis, G.; Morosuk, T.; Carassai, A. Conventional and advanced exergetic analyses applied to a combined cycle power plant. Energy 2012, 41, 146-152. [CrossRef]

34. Tsatsaronis, G.; Morosuk, T. Advanced exergetic analysis of a novel system for generating electricity and vaporizing liquefied natural gas. Energy 2010, 35, 820-829. [CrossRef] 